\title{
In Vitro Evaluation of Cytotoxicity of Colloidal Amorphous Silica Nanoparticles Designed for Drug Delivery on Human Cell Lines
}

\author{
Venugopal Balakrishnan, ${ }^{1}$ Hajarul Azwana Ab Wab, ${ }^{2}$ \\ Khairunisak Abdul Razak, ${ }^{1,2}$ and Shaharum Shamsuddin ${ }^{1,3}$ \\ ${ }^{1}$ NanoBiotechnology Research and Innovation (NanoBRI), Institute for Research in Molecular Medicine, \\ Universiti Sains Malaysia, 11800 Georgetown, Penang, Malaysia \\ ${ }^{2}$ School of Materials and Mineral Resources Engineering, Universiti Sains Malaysia, 14300 Nibong Tebal, Penang, Malaysia \\ ${ }^{3}$ School of Health Sciences, USM Health Campus, 16150 Kubang Kerian, Kelantan, Malaysia
}

Correspondence should be addressed to Shaharum Shamsuddin; shaharum@kb.usm.my

Received 13 July 2013; Revised 13 August 2013; Accepted 15 August 2013

Academic Editor: Haifeng Chen

Copyright (C) 2013 Venugopal Balakrishnan et al. This is an open access article distributed under the Creative Commons Attribution License, which permits unrestricted use, distribution, and reproduction in any medium, provided the original work is properly cited.

Silica nanoparticles are being developed and tested vigorously in drug delivery systems to treat various diseases. There are many advantages of using silica nanoparticles as a nanodelivery system because they are relatively inexpensive to produce, chemically inert, thermally stable and can be tailored to contain porous structures for drug encapsulation and to be hydrophilic for higher solubility in the human body. Despite these tremendous benefits, one of the pivotal requirements of these drug delivery systems is to be biocompatible with the human body. In this study, the cytotoxicity of colloidal amorphous silica nanoparticles synthesized using the micelle formation method has been tested against normal human foreskin fibroblast cell line (Hs27) as well as selected human bone carcinoma (U-2 OS), human breast cancer (MCF-7), and human cervical carcinoma (HeLa) and (Ca Ski) cell lines to determine the IC50 values. Two different sizes of silica nanoparticles, $20 \mathrm{~nm}$ and $40 \mathrm{~nm}$, were used to study the relationship between their size and the level of toxicity exerted on the different cells being tested. The cytotoxicity results indicated that $20 \mathrm{~nm}$ and $40 \mathrm{~nm}$ silica nanoparticles significantly reduce cell viability in a dose- and cell-type-dependent manner in the normal and cancerous cells tested.

\section{Introduction}

Nanomedicine is the application of nanotechnology or nanomaterials in the healthcare field. Nanomedicine as an evolution of the modern medicine has provided a different paradigm in the way the modern medical practitioners can approach or treat various illness or disorders. Nanomedicine has offered various tools to lift the limitations that have existed in the conventional medicine, hence ensuring higher success in the treatment and diagnosis of disease. One of the tools of nanomedicine being widely applied is nanodelivery systems to carry drugs into the human body $[1,2]$. There are various benefits of employing nanodelivery systems for drug delivery purposes. For instance, by reducing the size of the drugs into nanosized formulations, the drug dissolution rate can be increased, thereby improving the drug absorption and bioavailability in the body. Apart from that, drugs can be delivered at the desired site of action in the human body, thereby improving the therapeutic index of the drugs by increasing their efficiency and reducing their toxicity. For example, chemotherapeutic drugs administered at high dosages in the human body to destroy tumor cells can inadvertently destroy the surrounding healthy tissues or cells as well, thereby eliciting unwanted ill effects. Another major advantage of employing nanoparticle to deliver drugs is to provide protection for easily degraded or short half-life drugs, such as small peptides and nucleic acids to prolong the pharmacological effects.

Nanomaterials, engineered or synthesized for the purpose of delivering the drugs, are the major component of the drug delivery system which may ensure its success or failure. Nanomaterials used in nanodelivery systems can exist in 
various forms and types. Nanoparticles are a subset of nanomaterials which can be tailored for specific usage depending on the material and method of synthesis. Silica nanoparticle is a type of nanoparticle that is being developed and tested vigorously in drug delivery systems to treat various diseases [3-6]. There are many advantages of using silica nanoparticles as a nanodelivery system because they are relatively inexpensive to produce, chemically inert, and thermally stable. Apart from that, depending on the methods used to produce the silica nanoparticles, it can be tailored to contain porous structures for drug encapsulation and to be hydrophilic for higher solubility and stability in the human body.

Despite these tremendous benefits, one of the pivotal requirements of these drug delivery systems is to be biocompatible with the human body. Hence the nanoparticles used as a drug delivery system must be preferably nontoxic and must not elicit the body's natural immune responses at the doses administered. In other words, the nanoparticles should be considerably inert and any form of toxicity elicited at the intended target site, tissues, or cells should be solely due to the action of the drug molecules alone. This is important because if the nanoparticles exhibit high levels of toxicity, it will damage or kill healthy cells along with the diseased cells, and, by eliciting the body's natural immune responses, the nanoparticles will be effectively cleared by the macrophages in the circulation system before reaching the intended target. Therefore, preliminary studies must be conducted on the biocompatibility or cytotoxic potential of the nanoparticles on human tissues or cells as a basic prerequisite before it can be deemed to be utilized as a drug delivery system.

The cytotoxic potential of the nanoparticles can be mainly attributed to its physicochemical properties such as its size, shape, chemical purity, surface chemistry, and colloidal stability [7]. Much research has been done to relate the physicochemical properties of nanoparticles to their cytotoxicity. Because each type of nanoparticles has its own distinct physicochemical features, the toxic effects exerted on the cells may also vary. Some of the toxic effects are irreversible and permanent, leading to cell deaths and some are reversible; after the exposures to nanoparticles are removed, the cells may begin to proliferate normally. The mechanism of action that leads to the cells deaths may also be different. The toxic effect of the nanoparticles can be measured using in vitro cellbased assays [8].

In this study, the cytotoxicity of colloidal amorphous silica nanoparticles synthesized using the micelle formation method has been tested against normal human foreskin fibroblast cell line (Hs27) as well as selected human bone carcinoma (U-2 OS), human breast cancer (MCF-7), and human cervical carcinoma (HeLa) and (Ca Ski) cell lines to determine the IC50 values. Different sizes of silica nanoparticles were used to study the relationship between its size and the level of toxicity exerted on the different cells being tested.

\section{Materials and Methods}

2.1. Materials for Colloidal Silica Nanoparticles Synthesis. Vinyltrimethoxysilane (98\%) and Tween 80 were purchased from Sigma Aldrich. 2-Butanol, ammonia 35\%, and dialysis tubing $(12-14 \mathrm{KDa})$ were obtained from Fisher Scientific.

2.2. Synthesis and Characterization of Colloidal Silica Nanoparticles. Silica nanocolloids spheres were prepared by micelle formation approach, where Tween 80 anionic surfactant was introduced in the presence of water (solvent) and butanol (cosolvent), and ammonium was added to adjust the $\mathrm{pH}$. Typical preparation involved rapid mixing of reagents under vigorous stirring at room temperature of $24^{\circ} \mathrm{C}$. The mixture was then transferred into a preheated reactor. After an hour, vinyltrimethoxysilane (Si precursor) was added. The effect of Si precursor amount, butanol amount, and reaction temperature on the formation and size distribution of silica was studied. The mixture usually began to turn to a turbid white in about 5-15 min, as silica nanoparticles were formed. The mixture was left overnight with a continuous stirring rate of $320 \mathrm{rpm}$. The silica nanocolloids produced were then subjected to dialysis process for 4-5 days using dialysis tubing 12-14 KDa to remove the surfactant.

To investigate the relationship between the physicochemical properties and toxicities, characterization of the silica nanoparticles was performed using transmission electron microscopy (TEM), X-ray diffractometer (XRD), dynamic light-scattering (DLS) methods, and NIR-UV-Vis spectrophotometer, which provided information on the nanoparticles morphology, crystallinity, size distribution, and concentrations, respectively.

To investigate the morphology and size distribution of the silica nanoparticles, a drop of the particle suspension in the test medium was dried on a carbon-coated 200 mesh copper grid and imaged with a transmission electron microscope (Model FEI CM12 version 3.2 image analysis systems $120 \mathrm{kV}$ ). The images from TEM were analyzed using ImageJ software whereby 100 particles were measured. For X-ray diffraction (XRD) analysis, the samples were dried in an oven at $120^{\circ} \mathrm{C}$ overnight. XRD analysis was performed using $\mathrm{CuK} \alpha$ radiation from $5-90^{\circ}$ (Bruker AXS D8) to determine the crystallinity of silica nanoparticles. The images were analyzed with EVA software. Particles size distribution was evaluated using Zetasizer (Model ZEN 3600, Nanoseries, Malvern Instruments). The concentration of silica nanoparticles was measured by using UV-Visible near infrared spectrophotometer (UV-Vis 3600, Shimadzu), with absorbance value taken at peak of $233 \mathrm{~nm}$.

2.3. Human Normal and Cancer Cell Lines and Reagents. U-2 OS (HTB-96) human osteosarcoma, MCF-7 (HTB-22) human breast adenocarcinoma, HeLa (CCL-2) human cervical cancer, Ca Ski (CRL-1550) human cervical cancer, and Hs27 (CRL 1634) human foreskin fibroblast cell lines were all obtained from the American Type Culture Collection (ATCC), USA. The growth media: McCoy's 5a medium, Dulbecco's Modified Eagle Medium (DMEM), DMEM/F12 medium, RPMI 1640 medium, fetal bovine Serum (FBS), penicillin-streptomycin, and trypsin were obtained from Invitrogen, USA. The phosphate buffer solution (PBS) tablets were obtained from AMRESCO, USA. The cell proliferation reagent (WST-1) was obtained from Roche, USA. 
2.3.1. Cell Culture. MCF-7, HeLa, and Hs27 cells were maintained in DMEM. U-2 OS cells were maintained in McCoy's 5a medium. Ca Ski cells were maintained in RPMI 1640 medium. The cells were cultured in the appropriate medium, supplemented with $5-10 \%$ fetal bovine serum and $1 \%$ penicillin-streptomycin, using $25 \mathrm{~cm}^{2}$ flasks in a $37^{\circ} \mathrm{C}$ incubator with $5 \% \mathrm{CO}_{2}$ in humidified incubator.

2.3.2. Cell Subculture. To subculture the cells, the cells were divided and the culture medium was replaced with fresh medium as follows. First, the old medium was removed, and then the cells were rinsed briefly with PBS to wash the cells. One to two $\mathrm{mL}$ of trypsin was then added, and the flask was incubated at $37^{\circ} \mathrm{C}$ and $5 \% \mathrm{CO}_{2}$ for 5 minutes. After the cells had detached from the lower part of the flask, $20 \mathrm{~mL}$ of medium was added to the flask and the culture was divided in to two parts. One part was then transferred to a new flask.

2.4. Cell Proliferation Assay. The cells were grown until they were confluent. Then, the cells were trypsinised and the number of viable cells was counted with a hemocytometer to prepare a cell suspension. Two hundred microlitres of suspension containing $1 \times 10^{4}$ cells was seeded in each well of a 96-well microtiter plate (BD, USA) and incubated overnight at $37^{\circ} \mathrm{C}$ with $5 \% \mathrm{CO}_{2}$. In the following day, the medium was replaced and the cells were treated with silica nanoparticles with varying concentrations and maintained at $37^{\circ} \mathrm{C}$ with $5 \% \mathrm{CO}_{2}$ for 24-72 hours. After the incubation period, the old medium was discarded from the wells and rinsed with PBS before adding fresh culture medium with a final volume of $100 \mu \mathrm{L}$ per well. Then, $10 \mu \mathrm{L}$ of WST-1, cell proliferation reagent, was added to each well. The microtiter plate was then incubated again for 2 hours at $37^{\circ} \mathrm{C}$ with $5 \% \mathrm{CO}_{2}$. After the incubation period, the cell viability was measured using an ELISA reader (Multiskan Spectrum) at $450 \mathrm{~nm}$.

2.5. Statistical Analysis. The experiment was carried out in three replicates. Microsoft Excel templates were used for the collection of raw data and transformation of the data to the proper format for GraphPad Prism 5.0 software. Prism was used to calculate the concentrations associated with $50 \%$ viability (IC50 values) with 95\% confidence limits using a Hill function nonlinear regression analysis.

\section{Results and Discussion}

3.1. Synthesis and Characterization of Silica Nanoparticles. In this study, we synthesized colloidal amorphous silica nanoparticles of two different sizes for drug delivery purposes using the micelle formation method. Primarily, silica can be present in two forms, crystalline and amorphous. We selected amorphous form of silica because it has higher solubility in water as opposed to crystalline form of silica which has very low water solubility [9]. The solubility of amorphous silica in water at body $\mathrm{pH}$ is normally around $130-150 \mathrm{ppm}$ $(\mu \mathrm{g} / \mathrm{mL})[10]$. Apart from that, amorphous silica can dissolve into body fluid as silicic acid and is then removed through urine $[11,12]$. The micelle formation method was used to synthesize the silica nanoparticles because it produces more homogenous particle size distribution and can directly entrap drug molecules inside micelles structure before forming silica nanoparticles. Schematic diagram in Figure 1 illustrates the formations of silica nanoparticles using micelle formation approach. Silica nanoparticles form due to hydrolysis, alcohol condensation, and water condensation. Hydrolysis occurs when Si precursor, organosilanes reacts with water and 2butanol in the aqueous solvent and forms siloxane bridge (1). Hydrolysis process is enhanced with the addition of ammonia by producing more hydroxyl ions $\left(\mathrm{OH}^{-}\right)$to react with organosilanes. For alcohol and water condensations, silanols react with each other to form crosslinking between $\mathrm{Si}-\mathrm{O}-\mathrm{Si}$ chains until all Si precursors reacted (equations (2) and, see $(3)[13,14])$ :

hydrolysis:

$$
\mathrm{Si}(\mathrm{OR})_{4}+n \mathrm{H}_{2} \mathrm{O} \longrightarrow \mathrm{Si}(\mathrm{OR})_{4}-n(\mathrm{OH})_{n}+n \mathrm{ROH}
$$

alcohol condensation:

$$
\mathrm{Si}-\mathrm{OR}+\mathrm{HO}-\mathrm{Si} \longrightarrow \mathrm{Si}-\mathrm{O}-\mathrm{Si}+\mathrm{ROH}
$$

water condensation:

$$
\mathrm{Si}-\mathrm{OH}+\mathrm{HO}-\mathrm{Si} \longrightarrow \mathrm{Si}-\mathrm{O}-\mathrm{Si}+\mathrm{H}_{2} \mathrm{O}
$$

Both kinds of silica nanoparticles were observed to be spherical in shape under TEM as shown in Figure 2, with average size of $20 \mathrm{~nm} \pm 3.5 \mathrm{~nm}$ and $40 \mathrm{~nm} \pm 4.6 \mathrm{~nm}$, analyzed using Image J software whereby 100 particles were measured. The X-ray diffraction patterns of the silica nanoparticles are shown in Figure 3. XRD diffractogram shows that a broad peak is present at 2 theta $=10-30^{\circ}$ for both the silica nanoparticles, verifying it to be of amorphous structure. Particle size distributions for the $20 \mathrm{~nm}$ and $40 \mathrm{~nm}$ silica nanoparticles are shown in Figures 4(a) and 4(b), respectively. The $Z$ average hydrodynamic diameter and polydispersity index of the silica nanoparticles were measured by dynamic lightscattering techniques to determine the particle size distributions. The $Z$-average value and polydispersity index (PdI) value for $20 \mathrm{~nm}$ silica nanoparticles are $47.80 \mathrm{~nm}$ and 0.099 , respectively. The $Z$-average value and polydispersity index (PdI) value for $40 \mathrm{~nm}$ silica nanoparticles are $64.45 \mathrm{~nm}$ and 0.097 , respectively. The $Z$-average value for both the silica nanoparticles is larger compared to the primary diameter as determined by TEM. This is because the $Z$-average is a hydrodynamic parameter and is usually affected by surface charge of the particles as the samples were measured in its colloidal form whereas TEM measurements of the samples were taken in dry conditions. The graphs in Figures 4(a) and $4(\mathrm{~b})$ which exhibit narrow particle size distributions about an average value and a polydispersity index value of $<0.100$ for both the silica nanoparticles indicate that the particles are monodispersed. Monodisperse suspensions of nanoparticles contain particles of nearly the same size and are better suited for studying size-dependent toxic effects as opposed to using polydispersed suspensions of nanoparticles which may mask size effects. The concentration of silica nanoparticles was measured in absorbance (OD) taken at 


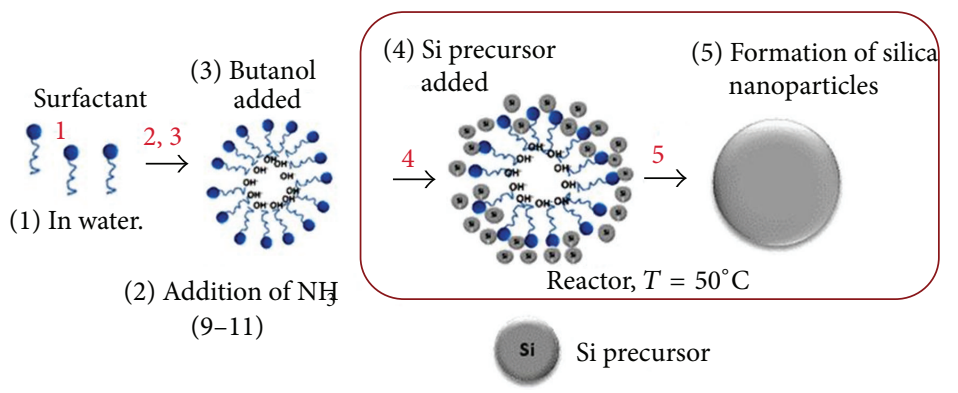

FIGURE 1: Formation of silica nanoparticles using micelle formation method.

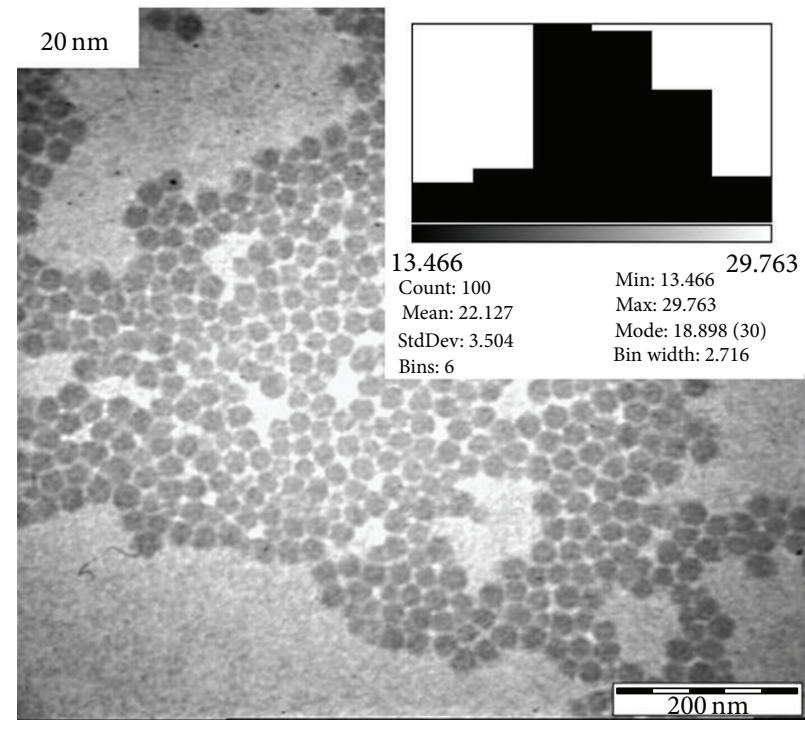

(a)

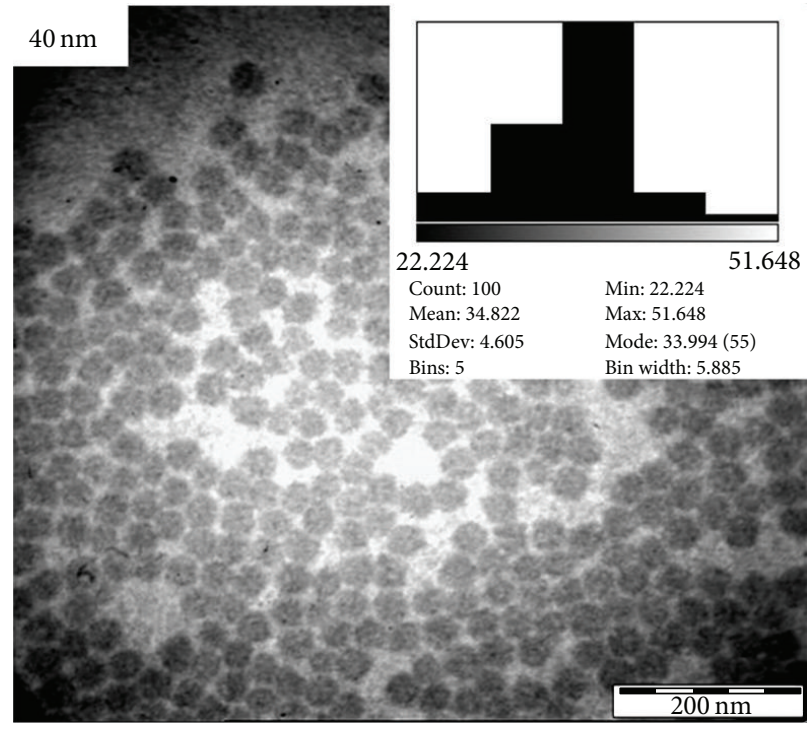

(b)

FIGURE 2: TEM images and histograms of particle size distribution from TEM analysis.

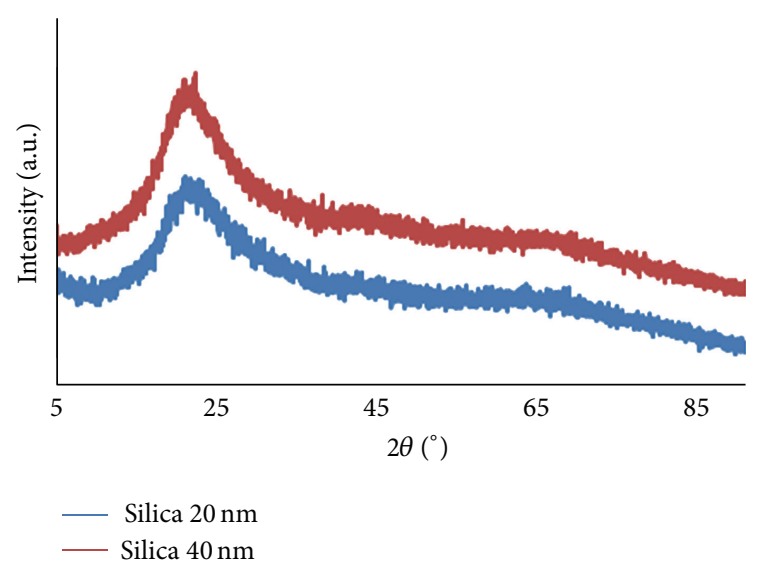

FIGURE 3: XRD patterns of colloidal amorphous silica nanoparticles.

a peak value of $233 \mathrm{~nm}$ by using UV-Visible near infrared spectrophotometer. The optical properties of silica nanoparticles are caused by surface defects related to large surface to volume ratio [15]. These structural defects are classified into paramagnetic and nonparamagnetic defects, which can be characterized by optical absorption in a broad range of wavelengths: near-infrared, visible, and ultraviolet (UV) [16]. A single absorption band was observed at $233 \mathrm{~nm}(\sim 5 \mathrm{eV})$ during photometric scanning of both the silica nanoparticles in the UV range as shown in Figure 5. This optical absorption band at $5 \mathrm{eV}$ is one of the oldest known nonparamagnetic defects in amorphous silica and also known as the " $B_{2}$ band." This band is attributed to occur due to some form of oxygen deficiency in the silica network $[17,18]$. Therefore, we were able to validate that the optical absorption exhibited at $233 \mathrm{~nm}$ was due to silica nanoparticles, hence rationalizing our method of measuring the concentration of colloidal silica nanoparticles in this manner. The absorbance values at peak $233 \mathrm{~nm}$ for $20 \mathrm{~nm}$ and $40 \mathrm{~nm}$ silica nanoparticles are tabulated in Table 2. From Figure 6, it can be seen that the intensity of the peak for $40 \mathrm{~nm}$ silica nanoparticles is slightly higher than $20 \mathrm{~nm}$ silica nanoparticles suggesting that bigger particles have higher UV absorption. Similar findings were reported by Rahman and coworkers who carried out experiments on size-dependent physicochemical and optical properties of silica nanoparticles. They have observed that 


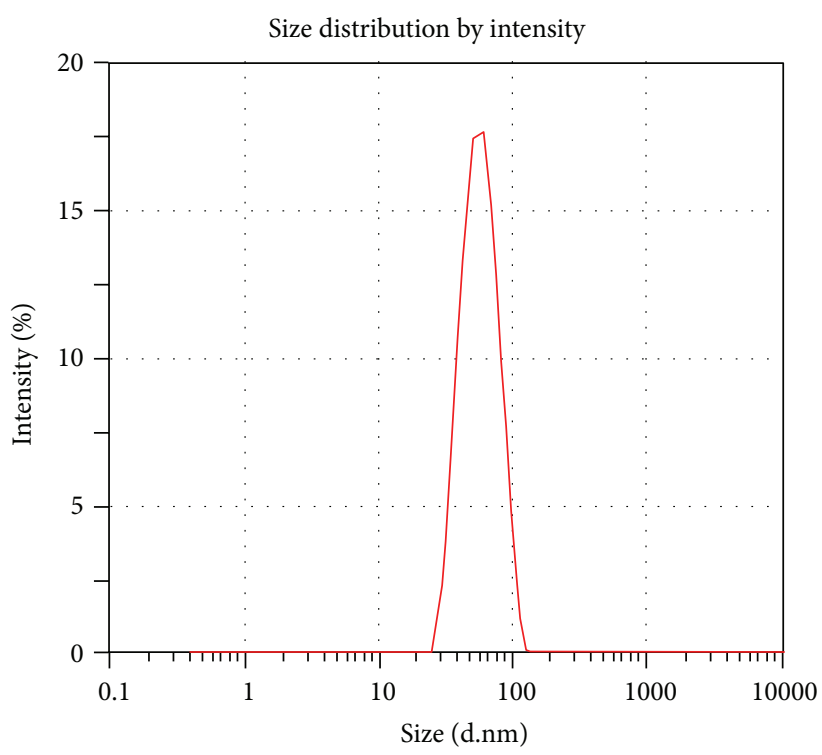

(a)

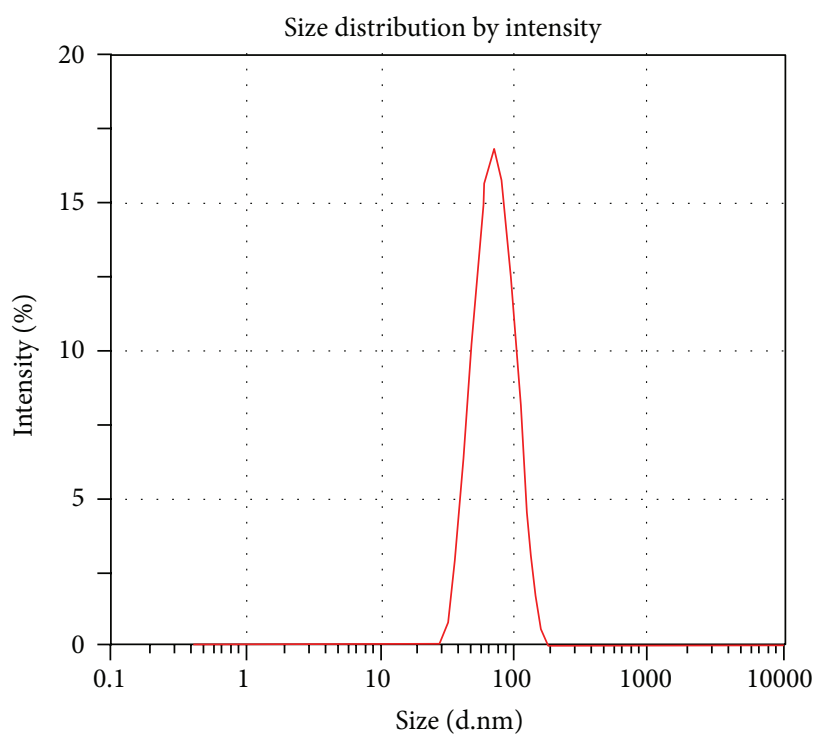

(b)

FIgURE 4: Particle size distribution of (a) $20 \mathrm{~nm}$ silica nanoparticles and (b) $40 \mathrm{~nm}$ silica nanoparticles.

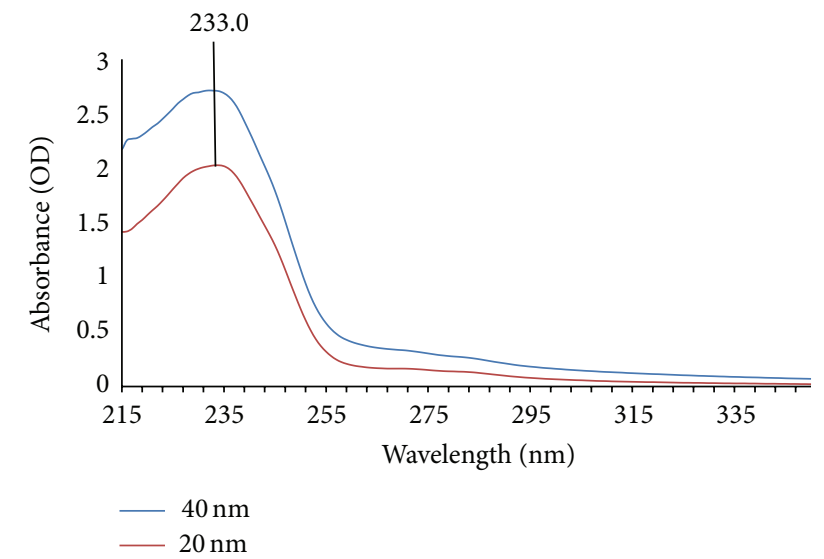

FIGURE 5: Optical absorption of $20 \mathrm{~nm}$ and $40 \mathrm{~nm}$ silica nanoparticles in UV range.

the intensity of the peak slightly decreases as the sizes of silica particles decrease and attributed their findings to the intense interparticle interactions at smaller particle size, that is, aggregation phenomena which could decrease the exposure of the E centers present at the silica surface to the UV light source [19].

3.2. Acute Cytotoxicity. To study the cytotoxic effect of the $20 \mathrm{~nm}$ and $40 \mathrm{~nm}$ colloidal amorphous silica nanoparticles against the selected normal and cancerous human cell lines, WST- 1 assay was used to measure the amount of cell viability. The cell lines used for this study are Hs27, U-2 OS, MCF7, HeLa, and Ca Ski. All the cell lines were exposed to the silica nanoparticles for a period of $24 \mathrm{~h}$ to measure the acute

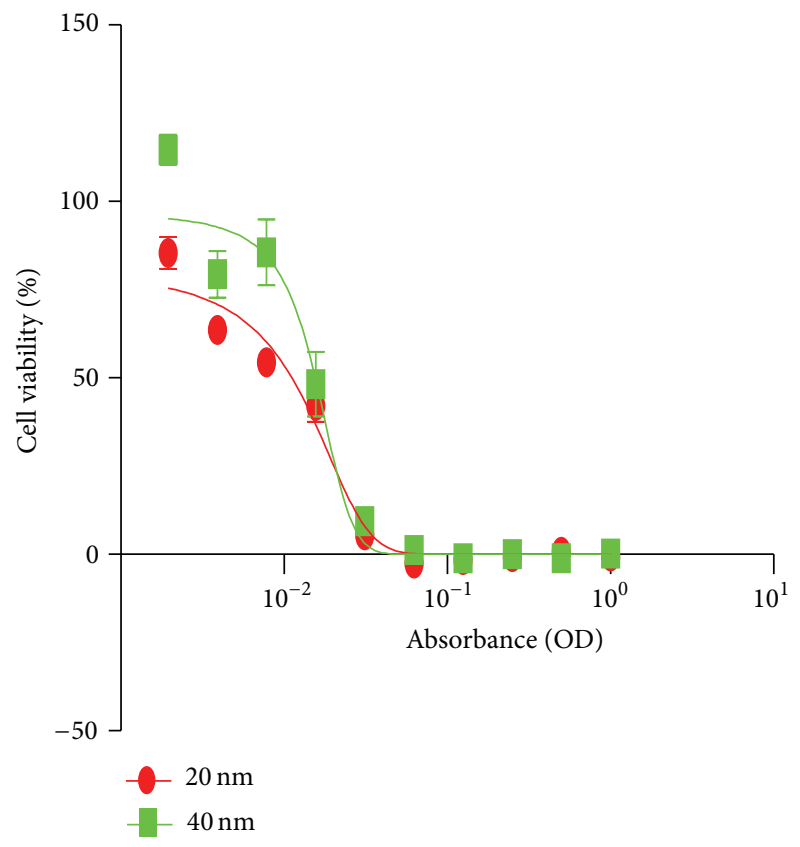

FIGURE 6: Cell viability assay for silica nanoparticles on U-2 OS cell line. The cell line was treated with $20 \mathrm{~nm}$ and $40 \mathrm{~nm}$ silica nanoparticles for $24 \mathrm{~h}$ with $\mathrm{IC}_{50}$ of $0.011 \mathrm{OD}$ and $0.015 \mathrm{OD}$, respectively.

cytotoxicity. Since the particles were produced in colloidal form, the concentration of the silica nanoparticles were measured in absorbance (OD) taken at a peak value of $233 \mathrm{~nm}$. Subsequently we have used the absorbance (OD) as a unit of particle mass concentration to perform the cytotoxicity testing with concentrations ranging from 1 to $0.002 \mathrm{OD}$. The results for the IC50 are also presented in absorbance (OD). 
TABLE 1: List of IC50 based on the size of nanoparticles and the cells tested.

\begin{tabular}{lcc}
\hline Cell lines & Size of nanoparticles $(\mathrm{nm})$ & IC50 (absorbance OD) \\
\hline \multirow{2}{*}{ U-2 OS } & 20 & 0.01118 \\
& 40 & 0.01555 \\
MCF-7 & 20 & 0.05408 \\
& 40 & 0.07288 \\
Hs27 & 20 & 0.01967 \\
& 40 & 0.01438 \\
HeLa & 20 & 0.09516 \\
& 40 & 0.08063 \\
Ca Ski & 20 & 0.03821 \\
& 40 & 0.02447 \\
\hline
\end{tabular}

TABLE 2: Absorbance values (OD) of $20 \mathrm{~nm}$ and $40 \mathrm{~nm}$ silica nanoparticles.

\begin{tabular}{lcc}
\hline $\begin{array}{l}\text { Blank silica NPs } \\
\text { colloids (nm) }\end{array}$ & $\begin{array}{c}\text { Absorbance value } \\
\text { at peak 233 nm } \\
(\mathrm{OD})\end{array}$ & $\begin{array}{c}\text { Absorbance value at peak } \\
233 \times \text { dilution factor 100 } \\
(\mathrm{OD})\end{array}$ \\
\hline 20 & 2.028 & 202.8 \\
40 & 2.713 & 271.3 \\
\hline
\end{tabular}

In our effort to correlate the effect of size of the silica nanoparticles to its cytotoxic potential, we have tried to standardize and control all the other physicochemical parameters that may exist between the different-sized nanoparticles used in this experiment as discussed in the characterization of nanoparticles section. To minimize variability in production process the same batch of synthesized silica nanoparticles was used to perform the cytotoxicity assays. Preliminary steps were taken to evaluate the suitability of using WST1-based assay in this study by measuring the interference of silica nanoparticles on WST-1 reagents and its reaction products for all the cell lines at the similar concentrations of silica nanoparticles used for the cytotoxicity assay before proceeding with the experiment. Also, appropriate blanks and controls were included when performing cytotoxicity assays. Hence, any interference that may exist during cytotoxicity testing attributable to factors other than size of the nanoparticles can be safely ruled out.

The acute cytotoxicity of the silica nanoparticles is presented as a percentage of the cell viability versus concentration in Figures 6 to 10. The IC50 values were calculated from the graphs to determine the concentration of the silica nanoparticles needed to inhibit $50 \%$ of the cells from proliferating. Table 1 presents the IC50 values of the silica nanoparticles. In this study, the silica nanoparticles have been proven to inhibit the proliferation of both the normal and cancer cell lines that were tested in a dose-dependent manner. This is evident: as the concentration of silica nanoparticles increases, the percentage viability of the cells decreases for all the cell lines tested as shown in Figures 6 to 10. Thus, our results are in general agreement with previously reported studies on the dose-dependent cytotoxicity of amorphous silica nanoparticles [20,21]. The results also reveal differences

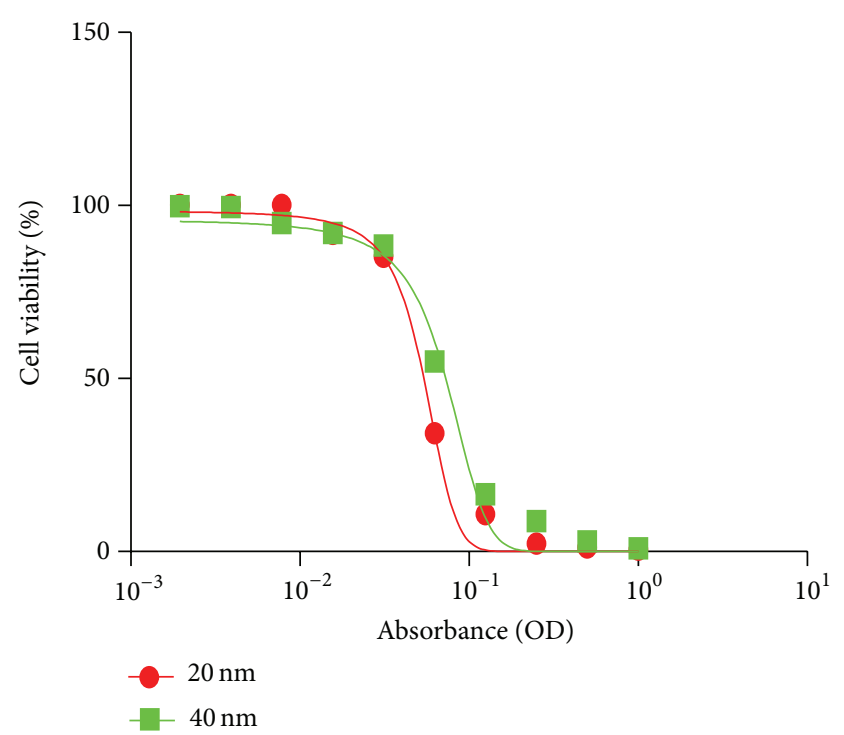

FIGURE 7: Cell viability assay for silica nanoparticles on MCF-7 cell line. The cell line was treated with $20 \mathrm{~nm}$ and $40 \mathrm{~nm}$ silica nanoparticles for $24 \mathrm{~h}$ with $\mathrm{IC}_{50}$ of $0.054 \mathrm{OD}$ and $0.072 \mathrm{OD}$, respectively.

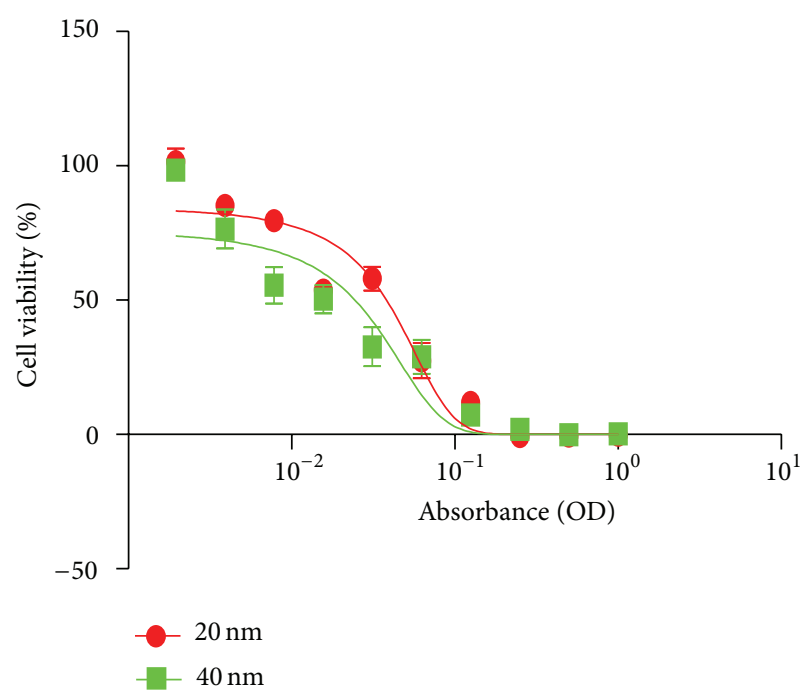

FIGURE 8: Cell viability assay for silica nanoparticles on Ca Ski cell line. The cell line was treated with $20 \mathrm{~nm}$ and $40 \mathrm{~nm}$ silica nanoparticles for $24 \mathrm{~h}$ with $\mathrm{IC}_{50}$ of $0.038 \mathrm{OD}$ and $0.024 \mathrm{OD}$, respectively.

in the responses among the five cell lines tested. Based on the results obtained, $20 \mathrm{~nm}$ nanoparticles were shown to be more toxic compared to $40 \mathrm{~nm}$ sized nanoparticles in U-2 OS and MCF-7 cell lines as shown in Figures 6 and 7, respectively. However, in both the human cervical cancer cell lines tested, Ca Ski and HeLa, as well as on Hs27 cell line, $40 \mathrm{~nm}$ nanoparticles were shown to be more toxic compared to $20 \mathrm{~nm}$ sized nanoparticles as shown in Figures 8, 9 and 10, respectively.

Thus, our data indicate that the size of silica nanoparticles does not relate to its cytotoxicity in a straightforward manner. In fact studies based on the size-dependent cytotoxicity of amorphous silica nanoparticles have produced contradictory 


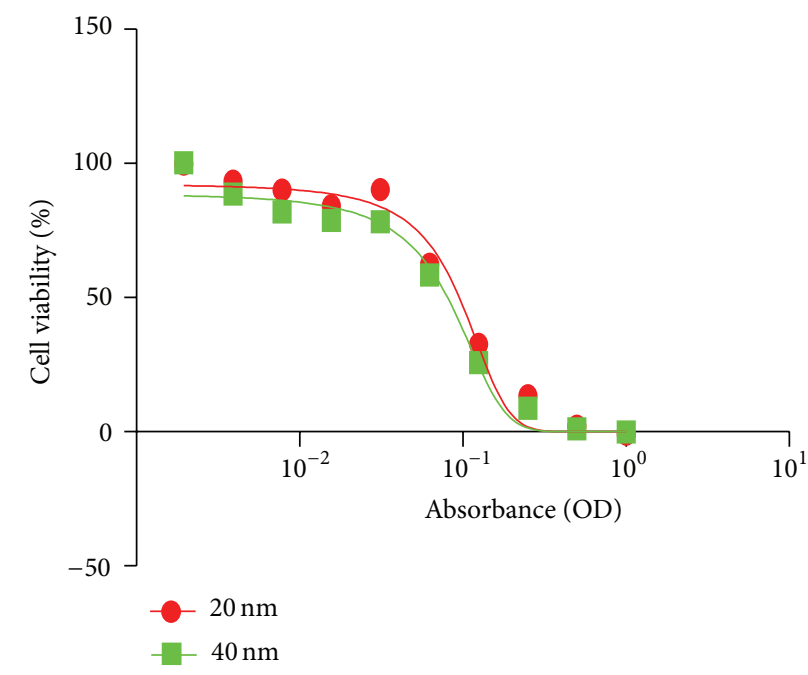

Figure 9: Cell viability assay for silica nanoparticles on HeLa cell line. The cell line was treated with $20 \mathrm{~nm}$ and $40 \mathrm{~nm}$ silica nanoparticles for $24 \mathrm{~h}$ with $\mathrm{IC}_{50}$ of $0.095 \mathrm{OD}$ and $0.081 \mathrm{OD}$, respectively.

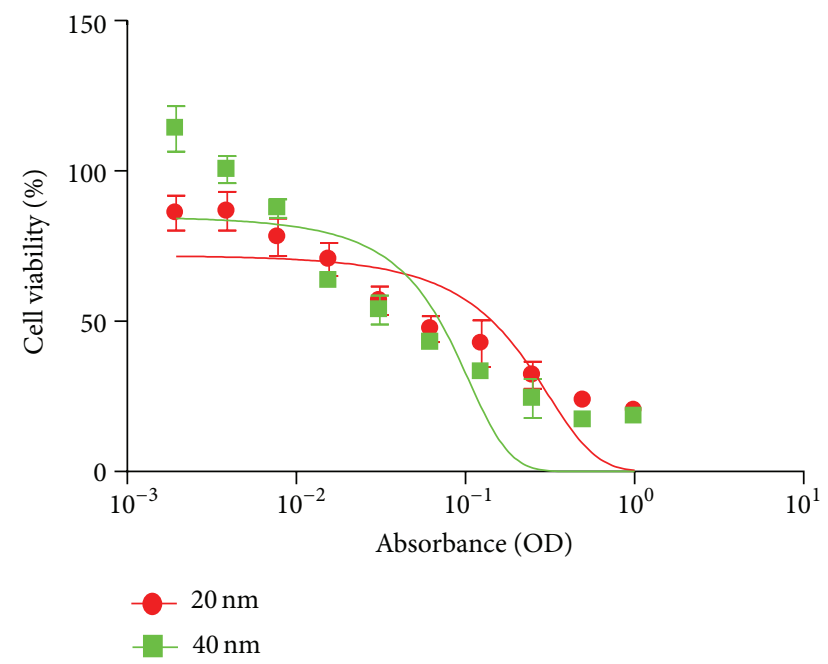

FIgURE 10: Cell viability assay for silica nanoparticles on Hs27 cell line. The cell line was treated with $20 \mathrm{~nm}$ and $40 \mathrm{~nm}$ silica nanoparticles for $24 \mathrm{~h}$ with $\mathrm{IC}_{50}$ of $0.019 \mathrm{OD}$ and $0.014 \mathrm{OD}$, respectively.

results. For example, several independent researchers have found that smaller-sized silica nanoparticles induced severe cellular damage in lung cancer cells, myocardial cells, and human endothelial cells [20-22]. This was attributed to the fact that smaller nanoparticles have larger ratio of surface area to weight, leading to more contact with the cells to induce damage [23-25]. This may explain our current findings of higher toxicity induced by $20 \mathrm{~nm}$ particles on MCF-7 and U-2 OS cell lines. On the other hand, some researchers have found that bigger-sized silica nanoparticles may exert higher toxicity against the cells tested. For instance, $\mathrm{Lu}$ and coworkers have reported that $20 \mathrm{~nm}$ silica nanoparticles are more cytotoxic than $7 \mathrm{~nm}$ particles on human hepatoma cells [26]. One possible explanation could be the protein corona formation on the surface of silica nanoparticles that may alter the cytotoxic potential of the nanoparticles. It has been established by numerous in vitro studies that various nanoparticles are able to adsorb serum proteins from tissue culture media, which affected the toxicity of the nanoparticles [27, 28]. Tenzer and coworkers have reported particle-size-dependent binding of several proteins involved in blood coagulation [29]. They studied the long-lived blood plasma-derived corona on monodispersed amorphous silica nanoparticles differing in size and observed that the type of nanoparticle corona formation is significant even if the size of the particles only differs in $10 \mathrm{~nm}$. Therefore it is possible that the type of protein corona formed on the $40 \mathrm{~nm}$ silica nanoparticles is significantly different from the one formed on $20 \mathrm{~nm}$ silica nanoparticles, thus rendering it to be more cytotoxic to Ca Ski, HeLa, and Hs27 cell lines. Since our results do not support size-dependent toxicity on the cell lines tested, the only other probable reason we could infer is that toxicity of silica nanoparticles is cell type dependent. Plausible explanation for this can be made on the basis that as different cell types have different physiological function, their interaction with nanoparticles can also differ considerably. These results are in line with those of Yu and coworkers, who demonstrated that the ability of silica nanoparticles to inhibit cell proliferation of macrophages and lung carcinoma cells was cell type dependent [30]. Similar findings were reported by kroll and coworkers who performed cytotoxicity screening of 23 engineered nanomaterials using a test matrix of ten cell lines and three different assays [31]. Their findings have suggested that even when assessing nanomaterials toxicity to cells originating from the same organ, the outcome highly depends on the cell type used and attributed the occurrence to sensitivity of cell lines.

\section{Conclusion}

The aim of this study was to assess the cytotoxic responses of five different human cell lines exposed to two differentsized monodispersed amorphous silica nanoparticles. In conclusion, we have demonstrated that $20 \mathrm{~nm}$ and $40 \mathrm{~nm}$ silica nanoparticles significantly reduce cell viability in a dose- and cell type-dependent manner in the normal and cancerous cells tested. Therefore, more research is necessary to investigate the underlying mechanisms of the cytotoxic effects of silica nanoparticles before they can be used in drug delivery and controlled release applications.

\section{Acknowledgments}

The authors appreciate technical support from the Electron Microscopy Facility, School of Biology, Universiti Sains Malaysia. This work was supported by Research University Grant (RU: 1001/Pbahan/814080).

\section{References}

[1] B. Mishra, B. B. Patel, and S. Tiwari, "Colloidal nanocarriers: a review on formulation technology, types and applications 
toward targeted drug delivery," Nanomedicine: Nanotechnology, Biology, and Medicine, vol. 6, no. 1, pp. 9-24, 2010.

[2] N. A. Ochekpe, P. O. Olorunfemi, and N. C. Ngwuluka, "Nanotechnology and drug delivery part 2: nanostructures for drug delivery," Tropical Journal of Pharmaceutical Research, vol. 8, no. 3, pp. 275-287, 2009.

[3] D. J. Bharali, I. Klejbor, E. K. Stachowiak et al., "Organically modified silica nanoparticles: a nonviral vector for in vivo gene delivery and expression in the brain," Proceedings of the National Academy of Sciences of the United States of America, vol. 102, no. 32, pp. 11539-11544, 2005.

[4] J. Lu, M. Liong, J. I. Zink, and F. Tamanoi, "Mesoporous silica nanoparticles as a delivery system for hydrophobic anticancer drugs," Small, vol. 3, no. 8, pp. 1341-1346, 2007.

[5] T. Y. Ohulchanskyy, I. Roy, L. N. Goswami et al., "Organically modified silica nanoparticles with covalently incorporated photosensitizer for photodynamic therapy of cancer," Nano Letters, vol. 7, no. 9, pp. 2835-2842, 2007.

[6] I. I. Slowing, J. L. Vivero-Escoto, C. W. Wu, and V. S. Y. Lin, "Mesoporous silica nanoparticles as controlled release drug delivery and gene transfection carriers," Advanced Drug Delivery Reviews, vol. 60, no. 11, pp. 1278-1288, 2008.

[7] P. Rivera-Gil, D. Jimenez de Aberasturi, V. Wulf et al., "The challenge to relate the physicochemical properties of colloidal nanoparticles to their cytotoxicity," Accounts of Chemical Research, vol. 46, no. 3, pp. 743-749, 2012.

[8] J. M. Hillegass, A. Shukla, S. A. Lathrop, M. B. MacPherson, N. K. Fukagawa, and B. T. Mossman, "Assessing nanotoxicity in cells in vitro," Wiley Interdisciplinary Reviews: Nanomedicine and Nanobiotechnology, vol. 2, no. 3, pp. 219-231, 2010.

[9] R. K. Iler, The Chemistry of Silica: Solubility, Polymerization, Colloid and Surface Properties, and Biochemistry, John Wiley \& Sons, New York, NY, USA, 1979.

[10] R. Viitala, S. Areva, M. Jokinen, and M. Koskinen, "About interactions between sol-gel derived silica, titania and living organisms," in Sol-Gel Methods for Materials Processing, P. Innocenzi, Y. Zub, and V. Kessler, Eds., vol. 15, pp. 251-268, 2008.

[11] J. F. Popplewell, S. J. King, J. P. Day et al., "Kinetics of uptake and elimination of silicic acid by a human subject: a novel application of 32Si and accelerator mass spectrometry," Journal of Inorganic Biochemistry, vol. 69, no. 3, pp. 177-180, 1998.

[12] W. Lai, P. Ducheyne, and J. Garino, "Removal pathway of silicon released from bioactive glass granules in vivo," Bioceramics, vol. 11, 1998.

[13] F. J. Arriagada and K. Osseo-Asare, "Synthesis of nanosize silica in a nonionic water-in-oil microemulsion: effects of the water/ surfactant molar ratio and ammonia concentration," Journal of Colloid and Interface Science, vol. 211, no. 2, pp. 210-220, 1999.

[14] R. Chen, H. Qu, A. Agrawal, S. Guo, and P. Ducheyne, "Controlled release of small molecules from silica xerogel with limited nanoporosity," Journal of Materials Science: Materials in Medicine, vol. 24, no. 1, pp. 137-146, 2013.

[15] A. Anedda, C. M. Carbonaro, F. Clemente, R. Corpino, and P. C. Ricci, "Low temperature investigation of the blue emission in mesoporous silica," Materials Science and Engineering C, vol. 25, no. 5-8, pp. 631-634, 2005.

[16] M. Jafarzadeh, I. A. Rahman, and C. S. Sipaut, "Optical properties of amorphous organo-modified silica nanoparticles produced via co-condensation method," Ceramics International, vol. 36, no. 1, pp. 333-338, 2010.
[17] L. N. Skuja, A. N. Streletsky, and A. B. Pakovich, "A new intrinsic defect in amorphous $\mathrm{SiO}_{2}$ : twofold coordinated silicon," Solid State Communications, vol. 50, no. 12, pp. 1069-1072, 1984.

[18] R. Tohmon, H. Mizuno, Y. Ohki, K. Sasagane, K. Nagasawa, and Y. Hama, "Correlation of the 5.0- and 7.6-eV absorption bands in $\mathrm{SiO}_{2}$ with oxygen vacancy," Physical Review B, vol. 39, no. 2, pp. 1337-1345, 1989.

[19] I. A. Rahman, P. Vejayakumaran, C. S. Sipaut, J. Ismail, and C. K. Chee, "Size-dependent physicochemical and optical properties of silica nanoparticles," Materials Chemistry and Physics, vol. 114, no. 1, pp. 328-332, 2009.

[20] W. Lin, Y. W. Huang, X. D. Zhou, and Y. Ma, "In vitro toxicity of silica nanoparticles in human lung cancer cells," Toxicology and Applied Pharmacology, vol. 217, no. 3, pp. 252-259, 2006.

[21] Y. Y. Ye, J. W. Liu, M. C. Chen, L. J. Sun, and M. B. Lan, "In vitro toxicity of silica nanoparticles in myocardial cells," Environmental Toxicology and Pharmacology, vol. 29, no. 2, pp. 131-137, 2010.

[22] D. Napierska, L. C. J. Thomassen, V. Rabolli et al., "Sizedependent cytotoxicity of monodisperse silica nanoparticles in human endothelial cells," Small, vol. 5, no. 7, pp. 846-853, 2009.

[23] A. Nel, T. Xia, L. Mädler, and N. Li, “Toxic potential of materials at the nanolevel," Science, vol. 311, no. 5761, pp. 622-627, 2006.

[24] H. M. Kipen and D. L. Laskin, "Smaller is not always better: nanotechnology yields nanotoxicology," The American Journal of Physiology_Lung Cellular and Molecular Physiology, vol. 289, no. 5, pp. L696-L697, 2005.

[25] G. Oberdörster, E. Oberdörster, and J. Oberdörster, "Nanotoxicology: an emerging discipline evolving from studies of ultrafine particles," Environmental Health Perspectives, vol. 113, no. 7, pp. 823-839, 2005.

[26] X. Lu, J. Qian, H. Zhou et al., "In vitro cytotoxicity and induction of apoptosis by silica nanoparticles in human HepG2 hepatoma cells," International Journal of Nanomedicine, vol. 6, pp. 18891901, 2011.

[27] T. Cedervall, I. Lynch, M. Foy et al., "Detailed identification of plasma proteins adsorbed on copolymer nanoparticles," Angewandte Chemie-International Edition, vol. 46, no. 30, pp. 5754-5756, 2007.

[28] E. G. Barrett, C. Johnston, G. Oberdörster, and J. N. Finkelstein, "Silica binds serum proteins resulting in a shift of the doseresponse for silica-induced chemokine expression in an alveolar type II cell line," Toxicology and Applied Pharmacology, vol. 161, no. 2, pp. 111-122, 1999.

[29] S. Tenzer, D. Docter, S. Rosfa et al., "Nanoparticle size is a critical physicochemical determinant of the human blood plasma corona: a comprehensive quantitative proteomic analysis," ACS Nano, vol. 5, no. 9, pp. 7155-7167, 2011.

[30] T. Yu, A. Malugin, and H. Ghandehari, "Impact of silica nanoparticle design on cellular toxicity and hemolytic activity," ACS Nano, vol. 5, no. 7, pp. 5717-5728, 2011.

[31] A. Kroll, C. Dierker, C. Rommel et al., "Cytotoxicity screening of 23 engineered nanomaterials using a test matrix of ten cell lines and three different assays," Particle and Fibre Toxicology, vol. 8, article 9, 2011. 

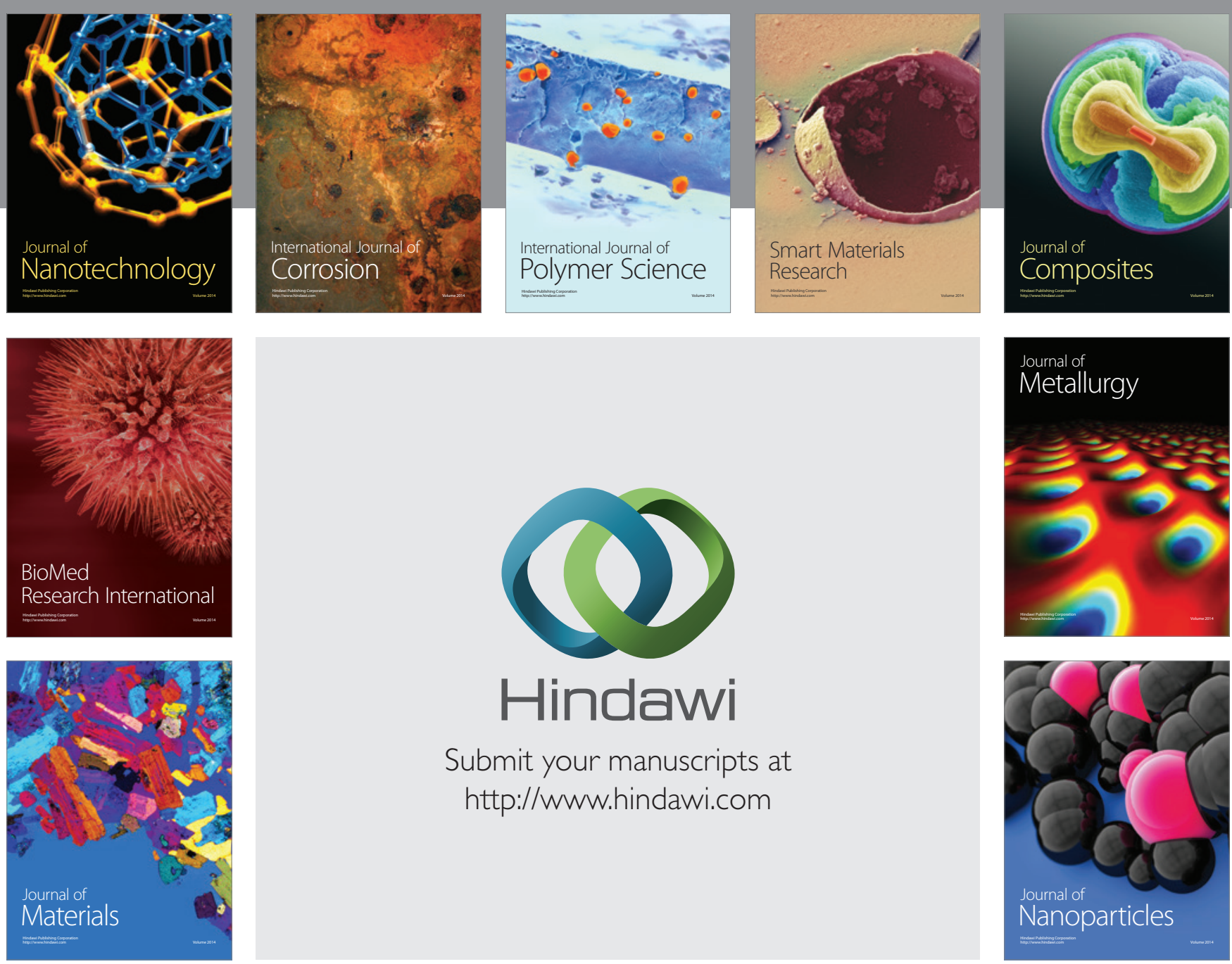

Submit your manuscripts at http://www.hindawi.com
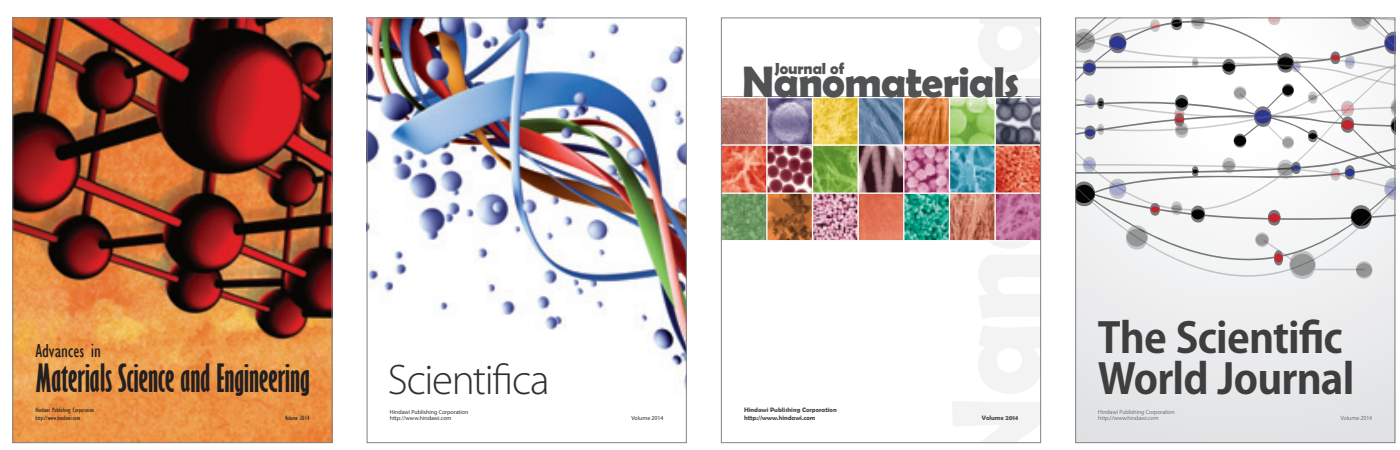

\section{The Scientific World Journal}
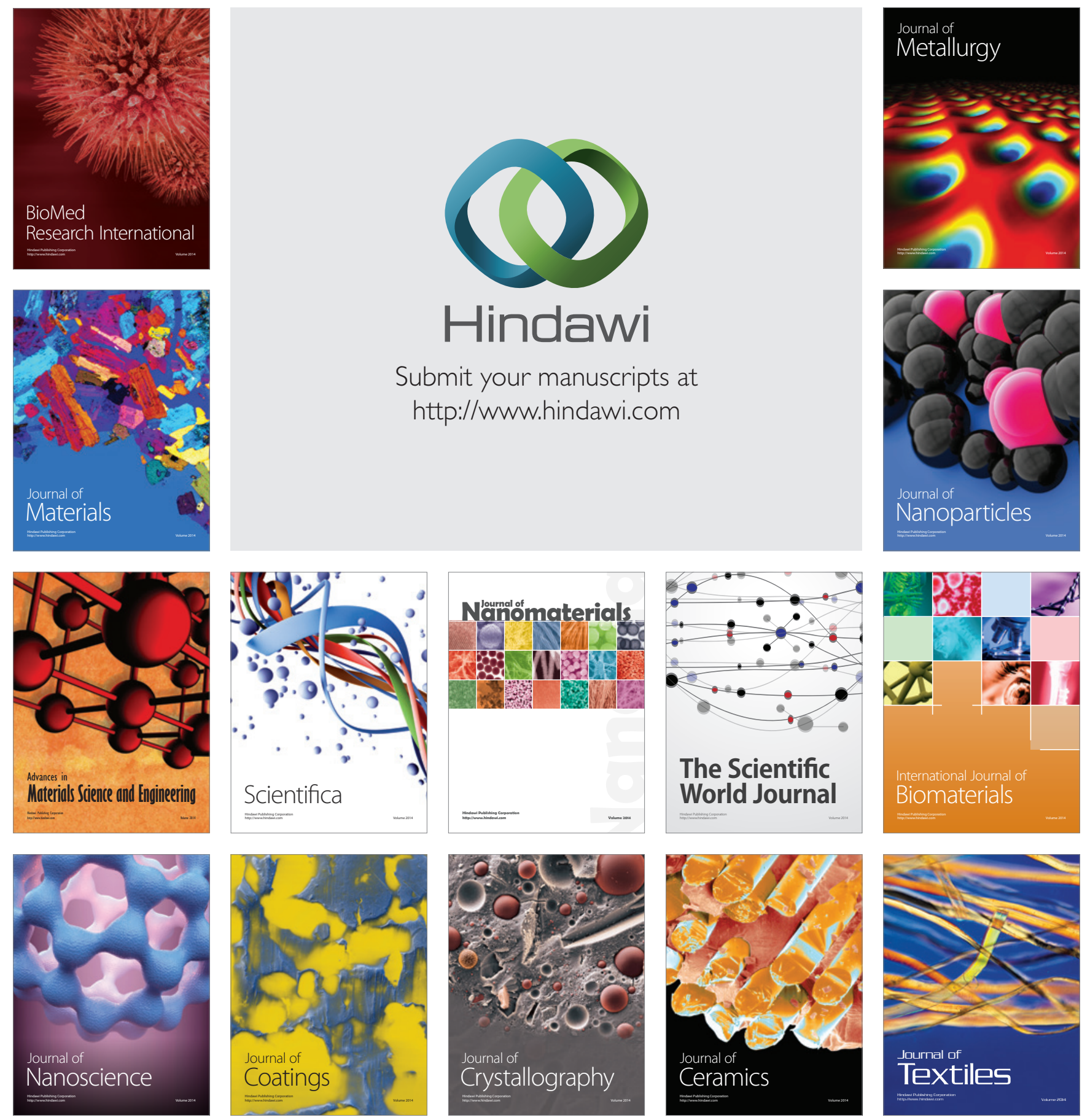